\title{
Assessing cervical stability: a reminder
}

\author{
Donald Emby, MB BCh, FF Rad (D) SA \\ Andrew Lancaster, $M B C h B$ \\ AngloGold Ashanti Health, Western Deep Levels Hospital, Carletonville
}

In patients with a neck injury, the recommendation that positive findings on standard radiographs, or negative findings but a strong clinical suspicion of injury, are indications for computed tomographic (CT) scan, remains current. ${ }^{1}$ Although CT scanning is invaluable for defining bony injury, its inability to satisfactorily demonstrate the spinal soft-tissue structures, particularly the ligaments, makes it an unsuitable modality for excluding instability, ${ }^{2}$ as the following case illustrates.

The patient, an underground mine worker, sustained an injury to his neck in a rock fall accident. Cervical spine radiographs and a CT scan demonstrate bilateral fractures which have resulted in disruption of the bony ring of $\mathrm{C} 2$. This constitutes a hangman's fracture (Figs 1 and 2).

The hangman's fracture (traumatic spondylolisthesis of the axis) represents fractures of the neural arch of C2 that are produced by a hyper-extension force. Although due to a rock fall in this case, it is an injury that is more commonly seen when the head or face hits the windshield or steering wheel in a motor car accident. The forced hyperextension results in bilateral fractures of the $\mathrm{C} 2$ neural arch. This is the same fracture as caused by judicial hanging, whence it derives its name. $^{3}$

Neurological consequences of the hangman's fracture are often less severe than may be anticipated, for two reasons. Firstly, the cervical cord occupies only approximately one-third of the antero-posterior diameter of the spinal canal at this level. Secondly, bilateral fractures of the posterior arch of $\mathrm{C} 2$ produce a decompression of the canal. These combine to spare the upper cervical cord. ${ }^{3}$

Our patient, who was neurologically intact, was treated with skull traction by means of cones calipers for 6 weeks and was then cautiously mobilised (out of bed) in a rigid neck brace. A repeat CT scan 6 months later demonstrates solid bony union at both the right and left $\mathrm{C} 2$ ring fracture sites (Fig. 3). The important question that should then be asked is: Does the demonstration of bony union mean that the injury is now stable?

Lateral views in flexion and extension are the recommended examination for assessing stability in the cervical spine and should be obtained in all patients in whom the need to exclude instability is clinically indicated. (They are not indicated in patients with clinically or radiographically unstable injuries.) The neck movements by the patient must be voluntary, and under no circumstances should an operator assist the patient with flexion or extension. The examination is also best carried out under the supervision of a radiologist or the attending doctor.

Figures $4 \mathrm{a}$ and $4 \mathrm{~b}$ show the cervical spine in extension and in flexion respectively. In extension, the gap between the anterior margin of the odontoid peg and the posterior margin of the anterior arch of $\mathrm{C} 1$ measures $1 \mathrm{~mm}$. However, in flexion the gap increases to $5 \mathrm{~mm}$.
In a normal adult, this gap should not exceed $2 \mathrm{~mm}$. The increased separation between the anterior arch of $\mathrm{C} 1$ and the odontoid peg in flexion indicates that there is residual hypermobility/instability present; by implication, this is due to (an additional) injury to the transverse ligament.

The answer to the question is therefore that the demonstration of bony union on CT scan does not necessarily indicate that a spinal injury is stable. One should remember that although CT scan demonstrates the bony structures in superb detail, it does not adequately assess the soft-tissue structures, particularly the ligaments. It is in fact possible to have a completely unstable spinal injury as a result of ligamentous injury, without any visible bony injury on plain film radiographs or CT scan. ${ }^{2}$

1. Lau L, ed. Imaging Guidelines. 3rd ed. Melbourne: Royal Australasian College of Radiologists, 1997: 156 (adopted by the Radiological Society of South Africa in 1999).

2. Harrison JL, Ostlere ST. Diagnosing purely ligamentous injuries of the cervical spine in the unconscious trauma patient. BJR 2004; 77: 276-278.

3. Grainger RG, Allison D, eds. Grainger \& Allison's Diagnostic Radiology: A Textbook of Medical Imaging. 3rd ed., vol. 2. New York: Churchill Livingstone, 1997: 1614-1615.

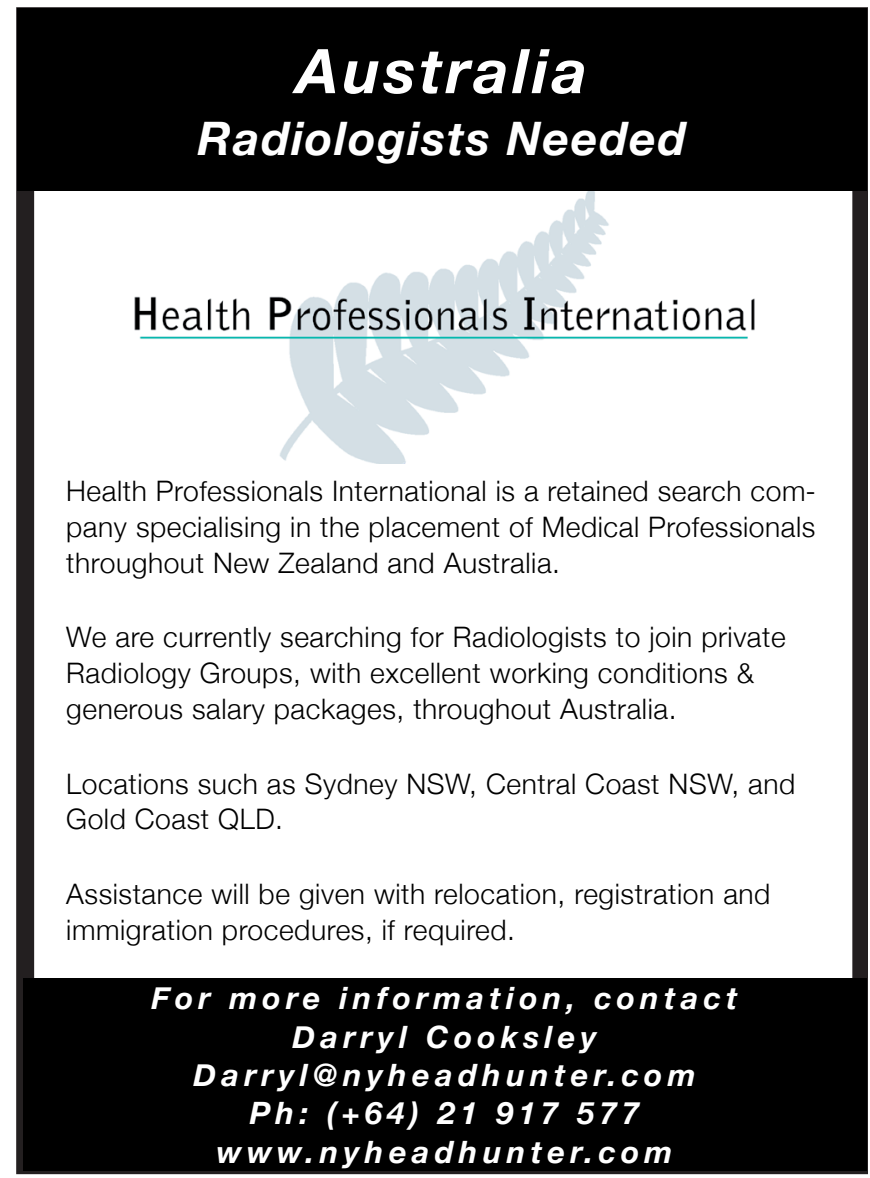




\section{CASE REPORT}

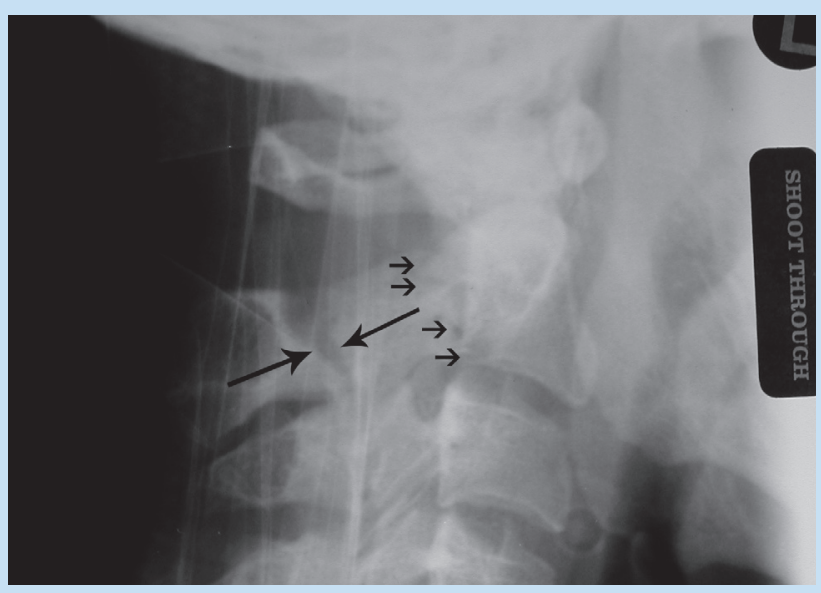

Fig. 1. Lateral shoot-through of the cervical spine. A broad vertical linear lucency (big arrows), which is consistent with posterior fracture of the C2 ring, is demonstrated. A more anterior fracture of the C2 ring is also faintly visible (small arrows).

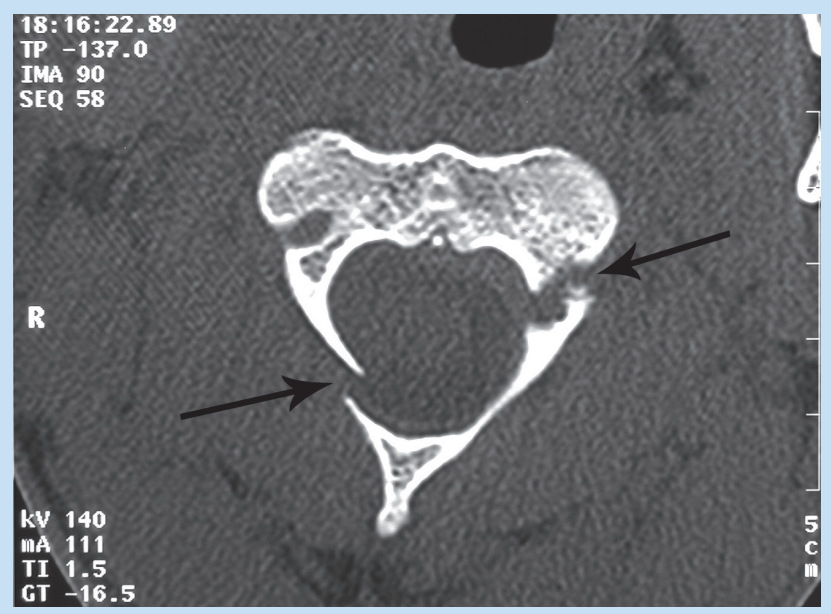

Fig. 2. CT scan through the body and dorsal ring of C2, showing fractures of the right lamina and left pedicle (arrows). (The classic hangman's fracture consists of fractures through the base of the posterior ring of $\mathrm{C} 2$ on both sides. As the fracture on the right side in this patient is more posteriorly situated, this could technically be described as a 'variant hangman's fracture'.)

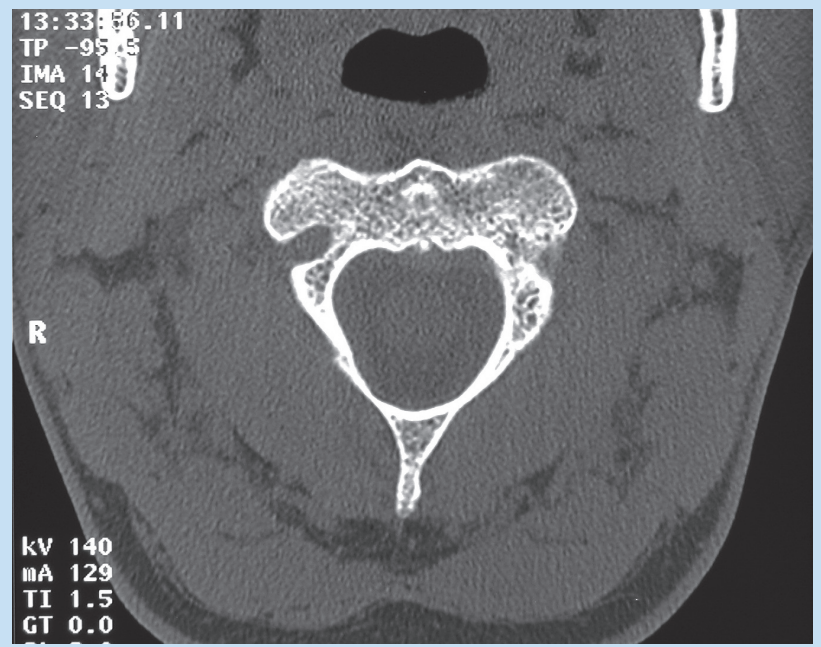

Fig. 3. CT scan through the body and dorsal ring of $C 2$ at same level as in Fig. 2, but 6 months later. Both fractures are shown to have healed.

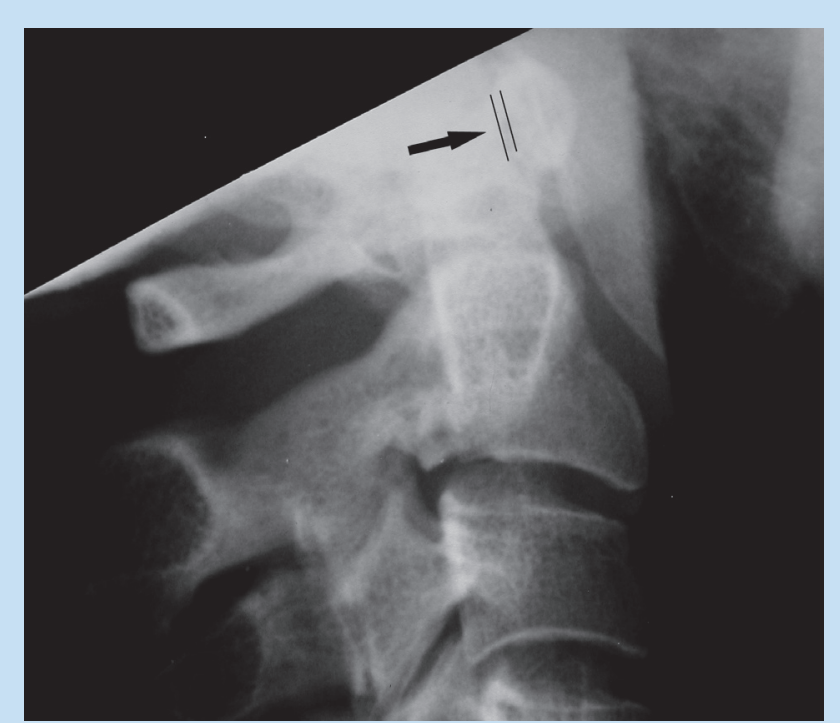

Fig. 4a. Lateral upper cervical spine in extension. The anterior cortical margin of the odontoid peg and the posterior cortical margin of the anterior tubercle of $\mathrm{C} 1$ have been highlighted and are indicated by the arrow. The gap between the odontoid peg and anterior tubercle of C1 measures approximately $1 \mathrm{~mm}$.

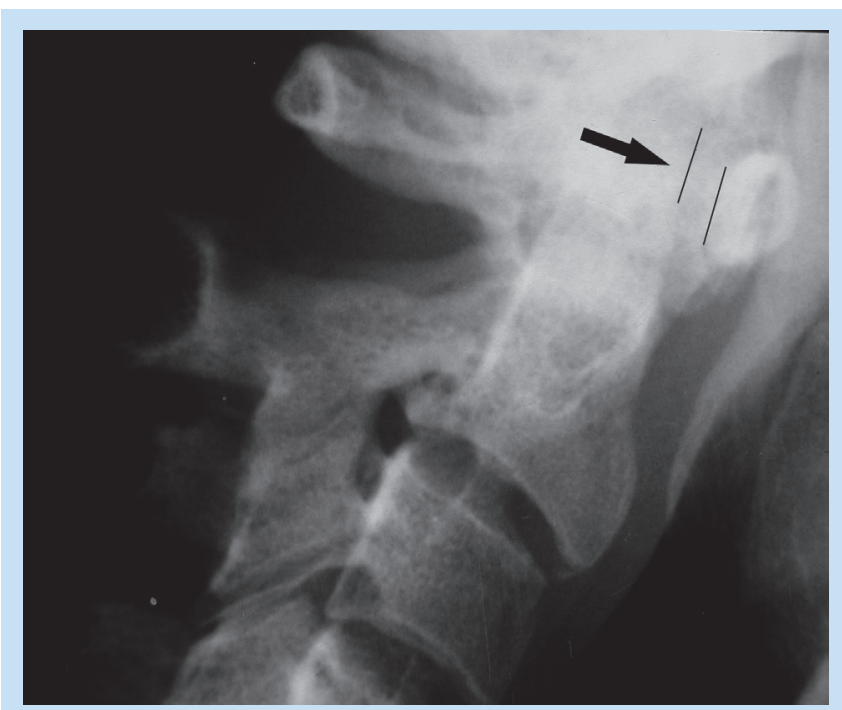

Fig. 4b. Lateral upper cervical spine in flexion. The gap between the odontoid peg and the anterior tubercle of C1 has increased significantly and now measures approximately $5 \mathrm{~mm}$. This indicates abnormally increased mobility (i.e. instability) of C1 on C2. 